\title{
Contribution of radar measurements to the inspection and condition assessment of railway bridges - case study at a historic masonry arch bridge in Oleśnica/Poland
}

\author{
Ch. Trela, J. Wöstmann \& S. Kruschwitz \\ Federal Institute for Materials Research and Testing (BAM), Germany
}

\begin{abstract}
Ground Penetration Radar (GPR) as a non-destructive (NDT)-method can be applied to obtain detailed information about the inner structure and condition of bridges without damaging the structure. In this paper the capabilities and limitations of the application of the fast inspection technique GPR will be demonstrated. In addition to GPR investigations, geoelectrical measurements, coring and petrophysical investigations have been carried out. The investigated railway bridge in Oleśnica is a typical European masonry arch bridge (age, construction and span length). It shows typical damage to the masonry arches such as increasing salt concentration, destruction, material losses and longitudinal cracks. Radar measurements were carried out with two main objectives: (1) Identification of basic geometric dimensions of the bridge and identification of construction details; (2) Evaluation of the condition of the masonry, such as mechanical damage (e.g. cracks) or variation of the moisture content. Radar antennas of different frequencies (having different penetration depths) have been used to estimate the thickness of the walls. Because of the high attenuation in the inner masonry structure the measurements have not produced satisfying results, but the radar measurements have been successfully applied to investigate the moisture distribution in the masonry. These results have been verified by coring and through geoelectrical measurements. Cracks were studied at two testing areas at one wing wall of the bridge using an automatic 2D radar scanning system. The radar data were processed using advanced data processing tools like FT-SAFT reconstruction and data fusion. The processing sequence allowed the creation of high-resolution depth sections (C-Scans).
\end{abstract}

Keywords: Ground Penetration Radar, spectral induced polarization, coring, railway bridge, non-destructive testing method, condition assessment. 


\section{Introduction}

With the planned traffic volume increase in Europe in the coming decades, especially in terms of speed and axle load, bridges as critical components in the transportation system are under the main focus [1]. Often bridges were constructed for lower axle loads and lower speeds. Exposure to environmental impact accelerates aging with an evolution of damage with time.

Efficient procedures of bridge inspection and condition and structural assessment, monitoring and repair strategies have become more important. In the case of railway bridges, one objective in the European research project Sustainable Bridges [1] was to improve and demonstrate the capability of nondestructive testing methods (NDT) towards meeting the specific requirements of the maintenance engineer as a precondition that these techniques will be stronger integrated into condition assessment systems.

The historic masonry bridge in Oleśnica/Poland is such a demonstration object. It represents a typical bridge of the existing rail network bridges in Europe carried out as masonry arch. Like many historic bridges, no reliable records of construction and early repair details exist. This lack of information, especially about inner structure and materials, complicates the condition assessment of bridges and otherwise extends the field of activity of NDT methods in civil engineering.

This paper presents a case study of GPR applications at a historic masonry bridge performed at two measurement campaigns in 2005 and 2006. The objective of the GPR survey in this study was to estimate structural information such as wall thickness and composition and condition assessment regarding moisture and crack distribution. In general, for condition and structural analysis, the application of only one testing method does not always give sufficient information. An efficient combination of NDT, minor-destructive (MDT) and in some cases of destructive methods (DT) adapted to the testing task is required (e.g. [2] and Maierhofer et al [3]). So, the following GPR measurements are also supported by other NDT and DT methods such as spectral induced polarization (SIP) measurement and coring. Additionally some laboratory tests will be presented demonstrating the investigation of material properties.

The results have been used by structural engineers of the Technical University of Wrocław (WUT) to carry out a strength assessment of this bridge.

\section{Bridge description}

The selected masonry bridge is located in Oleśnica, $40 \mathrm{~km}$ northeast of Wrocław. It belongs to the railway transportation system, which has only one track in use. This masonry bridge was constructed as from brickwork with one span and two tracks, see Figure 1, in 1875. The circular arch barrel covers a radius of nearly $5 \mathrm{~m}$. 


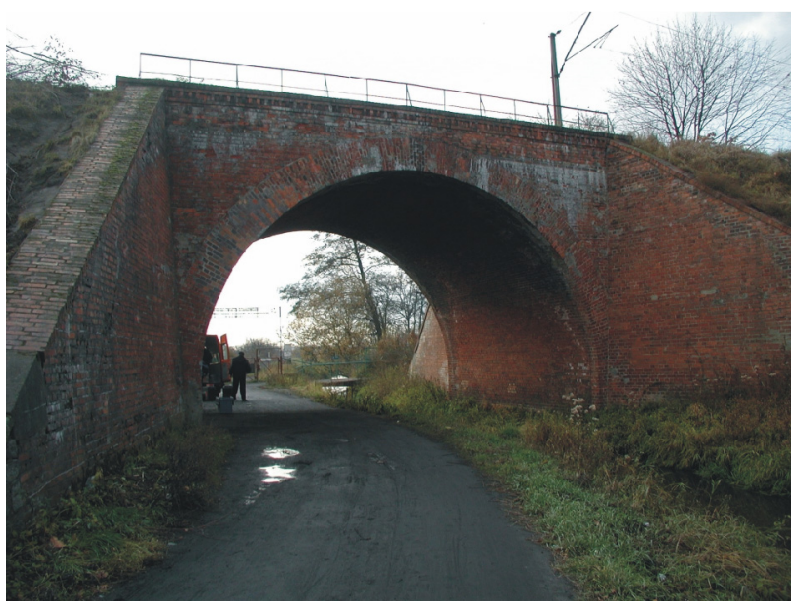

Figure 1: $\quad$ View of the railway bridge from Oleśnica.

\section{GPR data collection}

A SIR-20 GPR system was utilised for radar reflection measurements at different parts of the bridge such as the south abutment, left and right wing wall, at the arch and from the top of the bridge. Horizontal and vertical profiles were carried out with manual antenna movement and a mounted survey wheel for distance positioning or with an automatic scanning system, see Figure 2. The focused area was varied in depth using different antennas with central frequencies of $500 \mathrm{MHz}, 900 \mathrm{MHz}$ and $1.5 \mathrm{GHz}$. In Figure 3 two 2D radar testing areas on the left wing wall are shown beside borehole locations for core sampling and depth estimation to calibrate the velocity of penetrating electromagnetic waves and to validate GPR results.
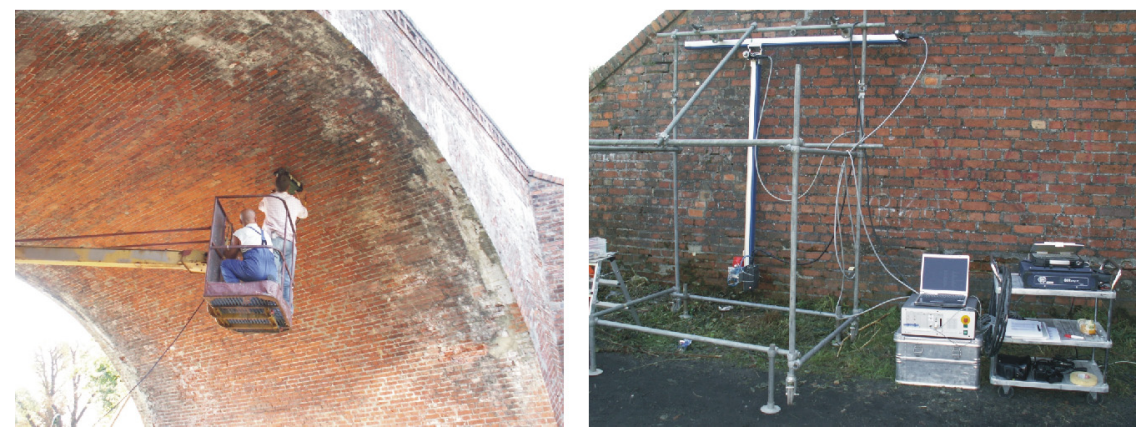

Figure 2: View of the radar measurements. Left: vertical and horizontal profiles under the arch with the $900 \mathrm{MHz}$ antenna. Right: testing area 1 using an automatic 2D radar scanning system with the 1.5 $\mathrm{GHz}$ antenna. 


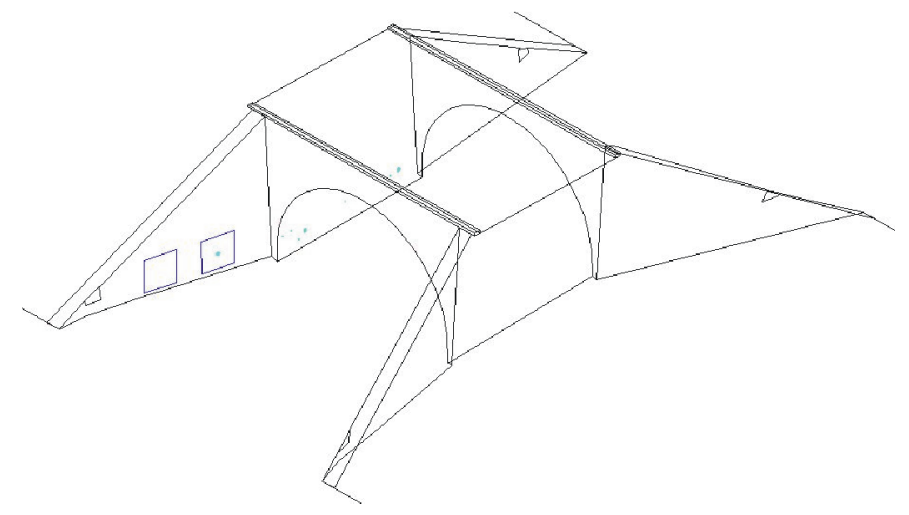

Figure 3: 3D-drawing of the geometry of the accessible structural elements of the bridge and of the $2 \mathrm{D}$ radar scanning measurements and borehole locations (marked with points).

\section{Data analysis and results}

\subsection{Structural elements}

In order to investigate the inner structure of the masonry arch bridge concerning the wall thickness and type of brickwork, recordings of radar antennas of different frequencies were analysed. The deeper the frequency, the higher the penetration depth of electromagnetic waves, but simultaneously the spatial resolution becomes less. As expected, reflection horizons of different brick layers and interference effects were observed at the radargrams at different times or after time-depth conversion at different depths. In general, the radargrams of 1.5 GHz antenna seem to best reproduce the first layers of the masonry structure. The missing backwall reflection at the thick wing walls and abutment with the deeper antenna frequency of $500 \mathrm{MHz}$ seems not to be caused by a weak reflection coefficient at the boundary between masonry and embankment but seems to be an effect of high attenuation in the inner masonry structure. This conclusion is supported by strong reflections at the expected boundary between the masonry and filling material of the embankment as shown in Figures 4-6, probably caused by water.

Coring at the left wing wall showed a wall thickness of $1.24 \mathrm{~m}$ and standing water behind the backwall. The wing walls and the abutments consist of massive brickwork of up to at least $1.88 \mathrm{~m}$, the drilling end at the south abutment. At the masonry surface, stretcher and header courses are visible alternately, supposing an English bond brickwork type.

Measurements from the inner part of the arch, below the bridge, show only backwall reflections near the ceiling, shown in Figure 4. This strong reflection at approximately $12 \mathrm{~ns}$ is visible at the horizontal profile over the whole width of the span, shown in Figure 5. The strong reflection hyperbola at $4.5 \mathrm{~m}$ could be caused by an internal spandral, but could not be confirmed by other measurements so far. 


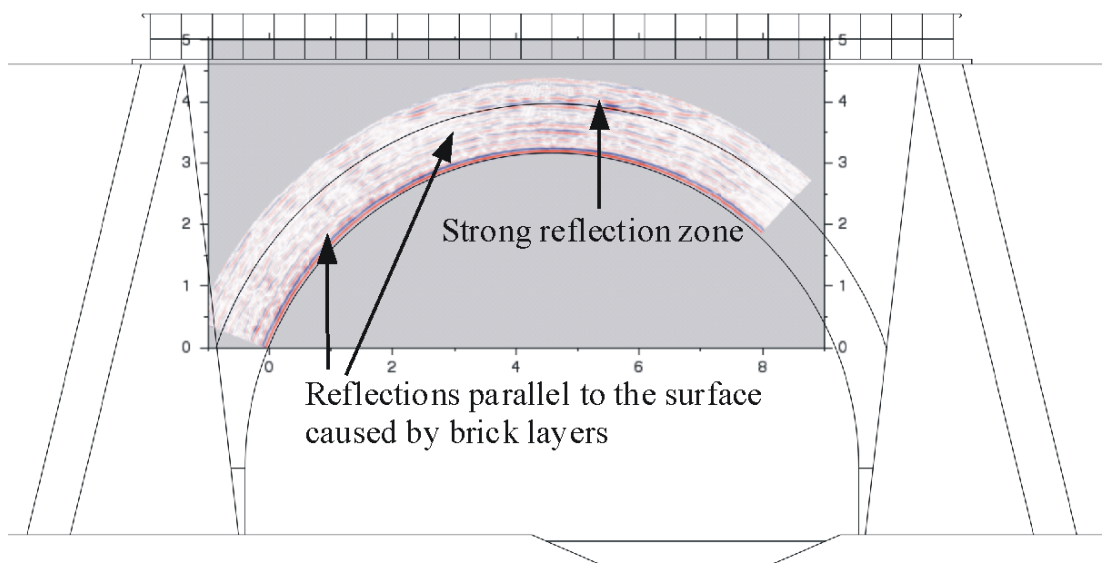

Figure 4: Radar measurement with the $900 \mathrm{MHz}$ antenna on the vertical profile V6m at the ceiling of the arch; radargram with radial positioned traces and topography with the schematic contour of the bridge.

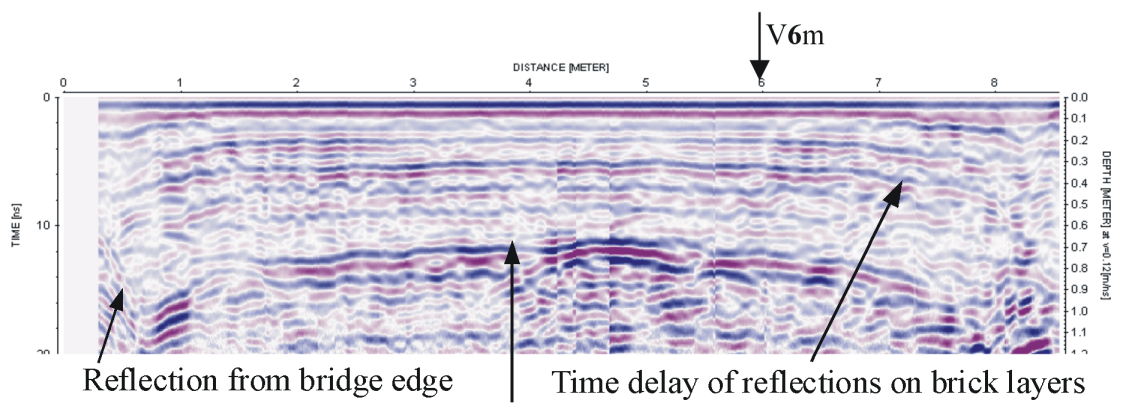

Strong reflection behind the inner masonry span

Figure 5: Radar measurement with the $900 \mathrm{MHz}$ antenna on the horizontal profiles at the ceiling of the arch with marked reflections and crossing profile V6m.

Radar measurements from the top of the bridge in Figure 6 allow a tracking of the strong reflection away from the midpoint of the bridge and could be interpreted as the course of the abutment of the bridge. The abutment seems to be thicker than $3 \mathrm{~m}$. Such thick abutments at historic masonry bridges are not unusual (Stromer [4]).

\subsection{Condition assessment concerning moisture}

The moisture distribution inside the masonry can be derived from the radargrams of the horizontal profiles at the bridge. Features like the time delay of reflection horizons near the bridge edges and areas of strong reflection of rather chaotic 
distribution probably combined with cracks hint to increased moisture. This qualitative result is supported by geoelectrical measurements of spectral induced polarization (SIP). These results have been verified and quantified by coring and moisture content estimation in the laboratory.

The following horizontal profile in Figure 7 shows exemplarily the capability of the radar measurements to detect differences in the moisture content inside masonry.

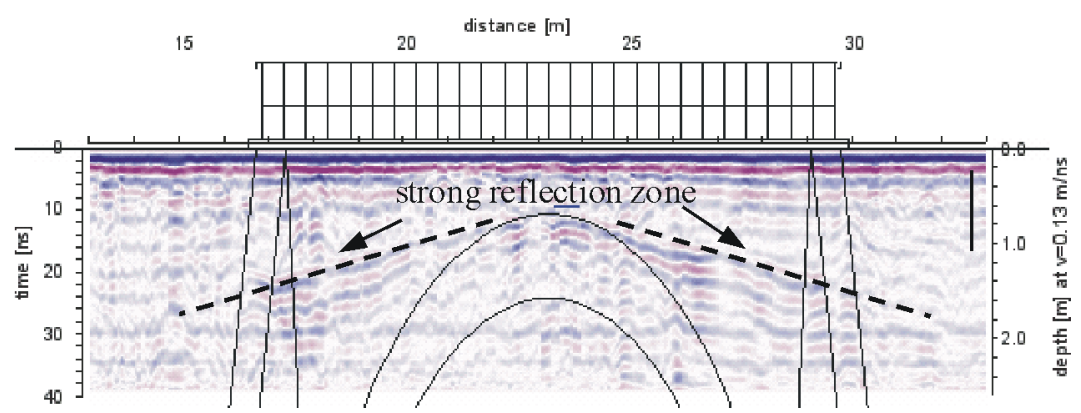

Figure 6: Radargram of the $500 \mathrm{MHz}$ antenna over the bridge with the schematic contour of the bridge; the assumed back wall of the abutment is marked with dashed line.

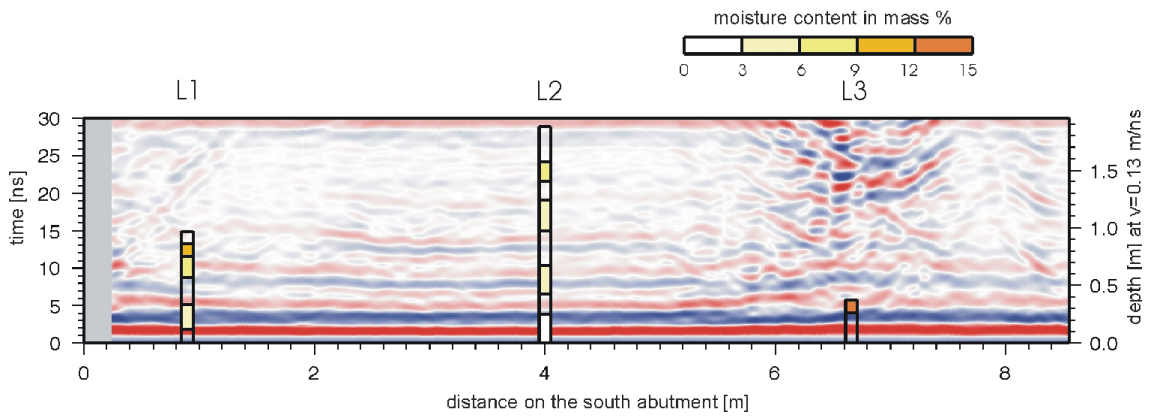

Figure 7: Radargram of the horizontal profile $\mathrm{H} 5$ recorded with the $500 \mathrm{MHz}$ antenna and results of the moisture content estimation on certain core samples at the south abutment in $1.20 \mathrm{~m}$ height.

Figure 7 contains the horizontal profile $\mathrm{H} 5$ at the height of $1.2 \mathrm{~m}$ at the south abutment and the results of the moisture content estimation of some core specimens from the boreholes L1, L2 and L3. Strong reflections and the time delay of the reflection horizons correlate well with the increased moisture content in the depth, especially the area between 5.5 and $7.5 \mathrm{~m}$ and near the edge at $1 \mathrm{~m}$. At borehole L3, at $6.66 \mathrm{~m}$ already after the first, rather dry brick of $25 \mathrm{~cm}$, a wet brick was met and no further drilling was possible. At the second core sample of this borehole L3 a maximum moisture content of 14.33 mass percent was estimated. The observed time delays of reflection horizons at the 
beginning and end of the radargrams relate to increased moisture at the edges of the bridge, see moisture content in Figure 7 at borehole L1.

The area between 5.5 and $7.5 \mathrm{~m}$ with strong reflection in the radargrams correlates well with the decreased thickness of the area with high resistivity in the SIP inversion result in Figure 8 and could be caused by wet and deteriorated masonry. Both the analysed amplitude and phase of the resistivity are characterised by changes after $5 \mathrm{~m}$ distance.

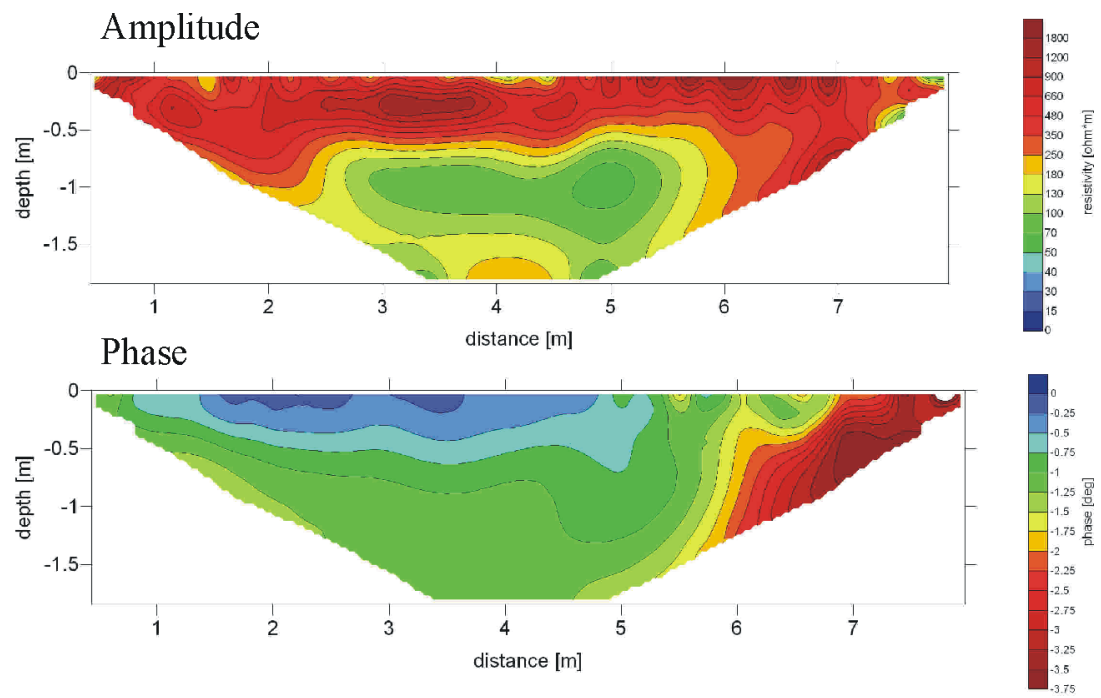

Figure 8: $\quad$ SIP inversion result of the amplitude (top) and phase (bottom) of the horizontal profile at the south abutment.

\subsection{Condition assessment concerning cracks}

To investigate the crack distribution in the masonry with GPR in more detail, an automated scanning system was applied to get more accurately positioned data in a shorter time. Two testing areas of $1.6 \mathrm{~m} \times 1.6 \mathrm{~m}$ at the left wing wall were selected in Figure 3. As shown in Figure 9, testing area 1 exhibits the stronger deteriorated area with visible open cracks especially in the left upper part and in the first lower brick layers and areas of repaired brickwork (new bricks and mortar).

33 vertical and horizontal profiles of $5 \mathrm{~cm}$ distance were recorded. After some standard data processing steps like cutting and sorting the profiles, the vertical and horizontal radar data were separately reconstructed with the 3D FT-SAFT algorithm (Mayer et al [5]). In the next step the vertical and horizontal profiles were combined using the maximum amplitude of the reconstructed data with a data fusion tool (Kohl et al [6]). 

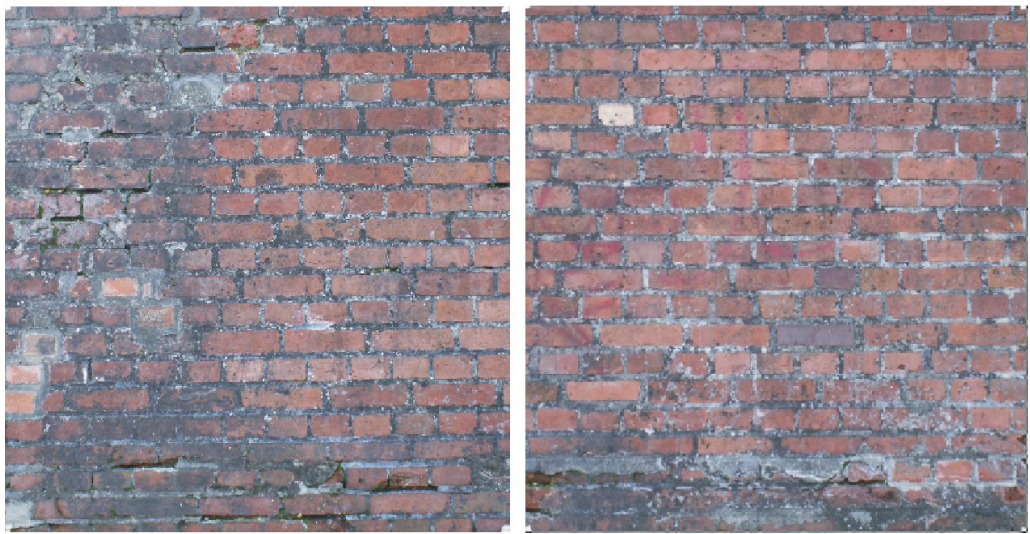

Figure 9: $\quad$ View on the brickwork of the radar testing area 1 and testing area 2 $(1.6 \times 1.6 \mathrm{~m})$ at the left wing wall.

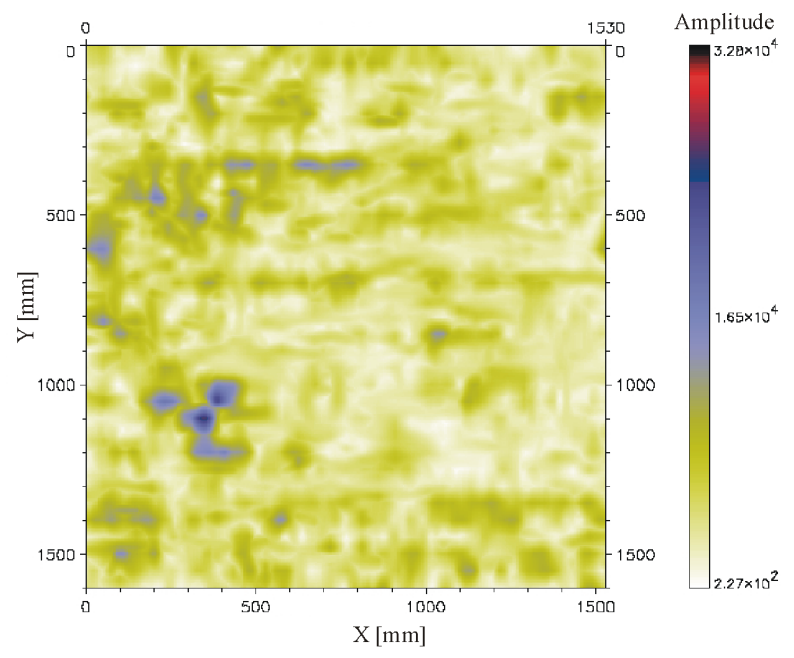

Figure 10: Times/depth section (C-Scan) at $14.5 \mathrm{~cm}$ of the testing area 1 after 3D FT SAFT reconstruction and data fusion of horizontal and vertical lines.

This processing sequence allowed the creation of high-resolution depth sections (C-Scans). An example of the testing area 1 is shown in Figure 10. At a depth of $14.5 \mathrm{~m}$, after one stretcher course, reflections of individual bricks are visible. The strongest reflections correlate well with areas of open cracks and the repaired area at the left side.

$3 \mathrm{D}$ visualisation of threshold values in different depth intervals with the AMIRA toolbox in Figure 11 shows that no tracking of cracks to the depth is possible. Strong reflections, marked green and red, correspond only to the brick geometry of the first brick layer (stretcher or header course). 


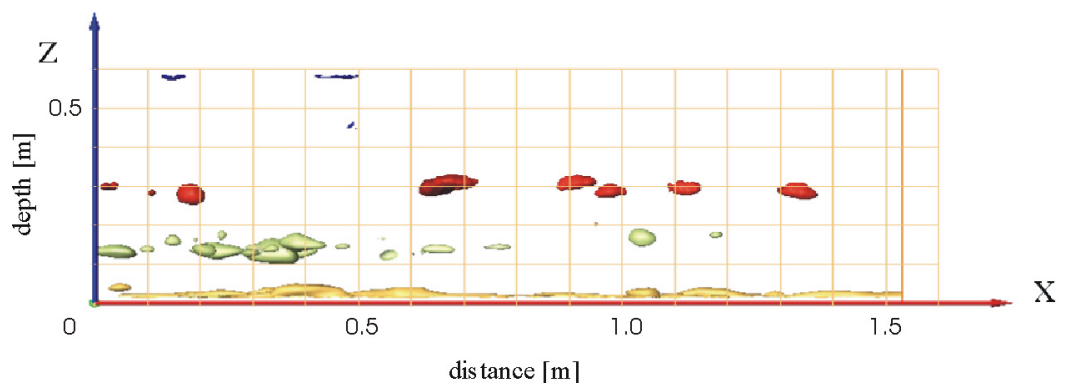

Figure 11: XZ-plot (B-Scan) of the 3D-visualisation of threshold values in different depth intervals of the testing area 1 after reconstruction and data fusion.

\section{Conclusions}

Ground penetrating radar (GPR), as a rapid and effective non-destructive testing method, can be used to evaluate the condition of a railway bridge made of brickwork. The reflected imaging of large measurement areas can provide indications of the structure of the bridge. To get information about the wall thickness, in the case of the masonry arch bridge in Oleśnica, measurements from top of the bridge with lower antenna frequencies $(500 \mathrm{MHz})$ were more successful than measurements directly on the bridge and with higher antenna frequencies due to strong attenuation in the brickwork. Generally, the accuracy of the depth estimation of inner structures is limited by variation of moisture content, which was quantified by moisture content estimation of core samples. Additionally, coring helps to calibrate the velocity of electromagnetic wave penetration in the material. Unfortunately, at the left wing wall, at the cored depth of $1.24 \mathrm{~m}$, no clear reflector was identified as back wall reflection.

In this case study, GPR has been used more successfully to distinguish between dry and undisturbed areas and wet areas combined with cracks. The last mentioned areas generate stronger reflections and affect a characteristic scattering pattern in the GPR data, shielding deeper areas from imaging. Changes in the moisture content are also detected by means of the geoelectrical measurements. These results are important to select the potential area of repair.

In practical operation it was demonstrated that the automated radar scanning systems provide very precisely positioned data of a high volume. Using the high antenna frequency of $1.5 \mathrm{GHz}$, reflections from the backside of the first brick layer, changing in stretcher or header course and cracks up to $50 \mathrm{~cm}$ are visible, enhanced in the case of increased moisture. Open cracks as water transportation paths behind the first brick layer are expected because of large areas at the surface with salt efflorescence. 


\section{Acknowledgements}

The authors gratefully acknowledge the very helpful assistance of the staff of the Polish Technical University of Wrocław and the Polish Railway Inspection department during data collection. European Commission funds the ongoing research project "Sustainable Bridges".

\section{References}

[1] EU-Project Sustainable Bridges, www.sustainablebridges.net

[2] SB-ICA, Guideline for Condition Appraisal and Inspection of Railway Bridges. In preparation in the project "Sustainable Bridges" within EU FP6, 2007.

[3] Maierhofer, Ch., Köpp, Ch., Binda, L., Zanzi, L., Santiago, J. R., Knupfer, B., Johansson, B., Modena, C., da Porto, F., Marchisio, M., Gravina, F., Falci, M., Galvez Ruiz, J. C., Tomazevic, M., Bosiljkov, V., Hennen, Ch., Project Report EUR 21696 EN - Onsiteformasonry project - On-Site investigation techniques for the structural evaluation of historic masonry buildings, European Commission, Luxembourg: Office for Official Publications of the European Communities: Brussels, pp. 1-141, 2006.

[4] Stromer, W. von, Pegnitzbrücke Nürnberg (Fleischbrücke). Steinbrücken in Deutschland, Beton-Verlag: Düsseldorf, pp.162-167, 1988.

[5] Mayer, K., Marklein, R., Langenberg, K. J. \& Kreuter, T., Threedimensional imaging system based on Fourier transformation synthetic aperture focusing technique. Ultrasonics, 28, pp. 241-255, 1990.

[6] Kohl, Ch., Krause, M., Maierhofer, Ch., Mayer, K., Wöstmann, J., Wiggenhauser, H., 3D-visualisation of NDT data using a data fusion technique, Insight 45, 12, pp. 800-808, 2003. 